\title{
The effect of parachlorophenylalanine
}

on the behaviour of cats

\author{
VALERIE J. HOYLAND, ELIZABETH E. SHILLITO AND MARTHE VOGT
}

Agricultural Research Council Institute of Animal Physiology, Babraham, Cambridge

\section{Summary}

1. Male and female kittens and adult cats were given $p$-chlorophenylalanine orally.

2. After treatment, some of the male cats showed mounting behaviour and the kittens and non-oestrous females showed an increase in treading and rubbing which was similar to one aspect of pro-oestrus behaviour.

3. The treated animals also appeared to suffer from skin irritation and showed increased restlessness which accompanied sleep deprivation.

4. Injection of 5-hydroxytryptophan stopped abnormal sexual activity and restored normal sleep for about 5 hours.

5. It is concluded that 5-hydroxytryptamine-containing neurones inhibit sexual behaviour in cats and that this role can be seen in male and, to some extent, also in female animals.

\section{Introduction}

The role of 5-hydroxytryptamine in the behaviour of animals has been more clearly understood since Koe \& Weissman (1966) reported that, in rodents, $p$-chlorophenylalanine depleted the brain of 5-hydroxytryptamine while leaving noradrenaline and dopamine relatively unaffected. Delorme, Froment \& Jouvet (1966) found that two intraperitoneal injections of $p$-chlorophenylalanine $(300 \mathrm{mg} / \mathrm{kg})$ reduced sleep in cats. Seventy-two hours after the first injection all sleep was absent and paradoxical sleep returned before slow sleep. After 10 days the cats were sleeping normally. These results were confirmed by Koella, Feldstein \& Czicman (1968) who also reported that the cats miaowed a great deal and lay down in a curled position as if to sleep, but they kept getting up and moving to a different place every few seconds. These authors found that slow sleep could be restored by administration of 5-hydroxytryptophan.

Work with rodents treated with $p$-chlorophenylalanine has shown that sensitivity to pain is increased (Tenen, 1967) and that morphine analgesia is antagonized (Tenen, 1968). As male rats treated with the drug showed an increase in sexual behaviour (Shillito, 1969, 1970 ; Sheard, 1969 ; Tagliamonte, Tagliamonte, Gessa \& Brodie, 1969), it was decided to observe groups of cats treated with $p$-chlorophenylalanine to study any changes in behaviour that might result.

\section{Methods}

Four groups of six cats were observed and treated as follows: 
Group 1: Kittens 3-4 months ; four females + two males of which two females + two males were treated.

Group 2: Kittens 3-4 months ; all males of which three were treated ; one died before treatment.

Group 3: Six adults ; two females watched between the ages of 13 and 15 months, and four males watched from 7 to 9 (one cat), 8 to 10 (two cats), and 14 to 16 months (one cat). All except one female were treated.

Group 4: Adults 7-9 months ; all males, of which five were treated.

Each group of cats lived freely in an observation room which was $3 \mathrm{~m}$ square. The room contained a bench with a sink along one wall and a metal tray about $1 \mathrm{~m}$ square in which hay was put for bedding, and two dirt boxes which contained sawdust. A wire cage was left open on the bench and this also contained hay. The cats were fed meat every morning and were given milk twice daily; water was also available. The lighting in the room was controlled by a time switch and the animals lived in white light from 4.30 to 16.30 and in red light from 16.30 to 4.30 . This arrangement was used because sexual behaviour in cats occurs more frequently in the evening and this lighting system provided some observation time in the dark as well as in the light. The cats were put in the observation room and left for 3 weeks to settle down. During the third week more frequent observations were made to note their normal activity and behaviour patterns. Observations were made through a one-way window in the door of the room. A microphone, suspended in the room and connected to an amplifier outside, was sometimes used to listen to the vocalizations of the cats. Before treatment started, specific behaviour patterns of the cats were recorded for periods of $1 \mathrm{~min}$ at $15 \mathrm{~min}$ intervals from about 10.00 to 17.30 ; once drug administration to any member of the group had begun, observation was mostly continuous between 10.00 and 17.30. However, recordings were made as before once every $15 \mathrm{~min}$ so that the maximal score for any activity was 4 per hour.

p-Chlorophenylalanine was given orally in capsules ; up to $400 \mathrm{mg}$ could be compressed into No. 1 size gelatin capsules. Two cats were given the drug at any one time. Some cats were treated more than once, but there was never less than 2 weeks between two drug administrations. One or two cats of each group remained untreated throughout and were used to determine the control values of cerebral 5-hydroxytryptamine. Several dose levels were tried; these were: $800 \mathrm{mg} / \mathrm{kg}$ given over 2 days in a dose of $(400 \mathrm{mg} / \mathrm{kg}) /$ day ; $600 \mathrm{mg} / \mathrm{kg}$ given over 2 days in a dose of $(300 \mathrm{mg} / \mathrm{kg}) /$ day, and single doses of 600,400 and $200 \mathrm{mg} / \mathrm{kg}$. 5-Hydroxytryptophan was given by intraperitoneal injection of $5 \mathrm{mg} / \mathrm{kg}$ or $2 \mathrm{mg} / \mathrm{kg}$. The compound was dissolved in $5 \mathrm{ml}$ saline and filtered through a Millipore syringe.

The effect of the various doses of $p$-chlorophenylalanine on the concentration of 5-hydroxytryptamine and 5-hydroxyindoleacetic acid in the brain of the cats was determined fluorimetrically (Ahtee, Sharman \& Vogt, 1970) at various intervals after drug treatment. The cats were anaesthetized with chloroform and bled to death by cutting the throat. The brain was taken out and the hypothalamus and the caudate nuclei were removed for the estimation of the amine and its metabolite. Part of the neo-cerebellum was used for recoveries and for the blank, because this region does not contain any 5-hydroxytryptamine. 
Results

Concentrations of 5-hydroxytryptamine and 5-hydroxyindoleacetic acid

p-Chlorophenylalanine lowered the concentration of 5-hydroxytryptamine (5-HT) in the brain samples to values ranging from 9 to $24 \%$ of that of the controls (Table 1). After the drug, the concentration of 5-hydroxyindoleacetic acid was too low to be detected by the method used. All the cats treated with $p$-chlorophenylalanine alone were killed when they were showing behavioural signs of drug action. There did not seem to be a direct correlation between the extent of behavioural change and the drop in 5-HT. There was no progressive lowering of 5-HT 2 or 3 days after the last dose, as Koe \& Weissman (1966) showed to occur in rats. One cat was given $p$-chlorophenylalanine $600 \mathrm{mg} / \mathrm{kg}, 48 \mathrm{~h}$ before an intraperitoneal injection of 5-hydroxytryptophan (5-HTP) $5 \mathrm{mg} / \mathrm{kg}$. It was killed $1 \mathrm{~h}$ after the second drug, and the cerebral concentration of $5-\mathrm{HT}$ was found to have returned to $58 \%$ of normal.

\section{Behavioural changes}

The cats needed at least 2 weeks to adapt to the living conditions of the observation room, the lighting, and the other cats of the group. The kittens made full use of the room quickly and learnt to jump onto the bench and onto a shelf and they were more active than the adult cats. Some of the adults never voluntarily climbed onto the bench, but once they were accustomed to the space they became more active and playful. Some of the animals were difficult to handle at first, but most of them became friendly and were eventually easy to dose and handle. A few cats reacted very quickly to the presence of observers outside the door, and would approach and rub against anyone who entered the room, whereas some animals always avoided contact as long as possible and showed very little response to people.

TABLE 1. Concentrations of 5-hydroxytryptamine in the combined caudate nuclei and hypothalamus of cats treated orally with p-chlorophenylalanine, corrected for losses.

\begin{tabular}{|c|c|c|c|}
\hline $\begin{array}{l}\text { Dose of } p \text {-chlorophenylalanine } \\
\text { in } \mathrm{mg} / \mathrm{kg} \text {, given orally }\end{array}$ & $\begin{array}{l}\text { Time after first } \\
\text { dose of PCPA }\end{array}$ & $5-\mathrm{HT} \mathrm{ng} / \mathrm{g}$ & $\begin{array}{l}\% \text { of mean } \\
\text { of controls }\end{array}$ \\
\hline 0 & & $\begin{array}{c}585 \\
429 \\
341 \\
645 \\
934 \\
\text { Mean }=587 \pm 102 *\end{array}$ & \\
\hline $\begin{array}{l}400+400 \\
300+300 \\
600 \\
600 \text { PCPA }+5-\text { HTP } 5 \mathrm{mg} / \mathrm{kg} \\
1 \mathrm{~h} \text { before death }\end{array}$ & $\begin{array}{l}48 \mathrm{~h} \\
48 \mathrm{~h} \\
48 \mathrm{~h} \\
48 \mathrm{~h}\end{array}$ & $\begin{array}{r}95 \\
50 \\
73 \\
339\end{array}$ & $\begin{array}{r}16 \\
9 \\
12 \\
58\end{array}$ \\
\hline $\begin{array}{l}400+400 \\
400+400 \\
300+300 \\
300+300 \\
300+300+5-\mathrm{HTP} 2 \mathrm{mg} / \mathrm{kg} \\
\quad 24 \mathrm{~h} \text { before death }\end{array}$ & $\begin{array}{l}72 \mathrm{~h} \\
72 \mathrm{~h} \\
72 \mathrm{~h} \\
72 \mathrm{~h} \\
72 \mathrm{~h}\end{array}$ & $\begin{array}{r}110 \\
92 \\
89 \\
59 \\
139\end{array}$ & $\begin{array}{l}19 \\
16 \\
15 \\
10 \\
24\end{array}$ \\
\hline $\begin{array}{l}400+400 \\
400+400 \\
400+400 \\
300+300 \\
300+300 \\
300+300\end{array}$ & $\begin{array}{l}96 \mathrm{~h} \\
96 \mathrm{~h} \\
96 \mathrm{~h} \\
96 \mathrm{~h} \\
96 \mathrm{~h} \\
96 \mathrm{~h}\end{array}$ & $\begin{array}{r}104 \\
107 \\
121 \\
102 \\
120 \\
92\end{array}$ & $\begin{array}{l}18 \\
18 \\
21 \\
17 \\
20 \\
16\end{array}$ \\
\hline
\end{tabular}

* S.E.M. 
The cats were generally active in the morning after the room had been cleaned and they had been fed. Then they would rest for periods which varied in length and become active again towards late afternoon when the lights were about to change. When resting, the cats curled up lying on their sides or stretched out completely relaxed, and generally their eyes were closed. Quite long periods were spent sitting upright or resting on the sternum, but in these postures the cats were alert and responded quickly to disturbance although their eyes might be shut at the time.

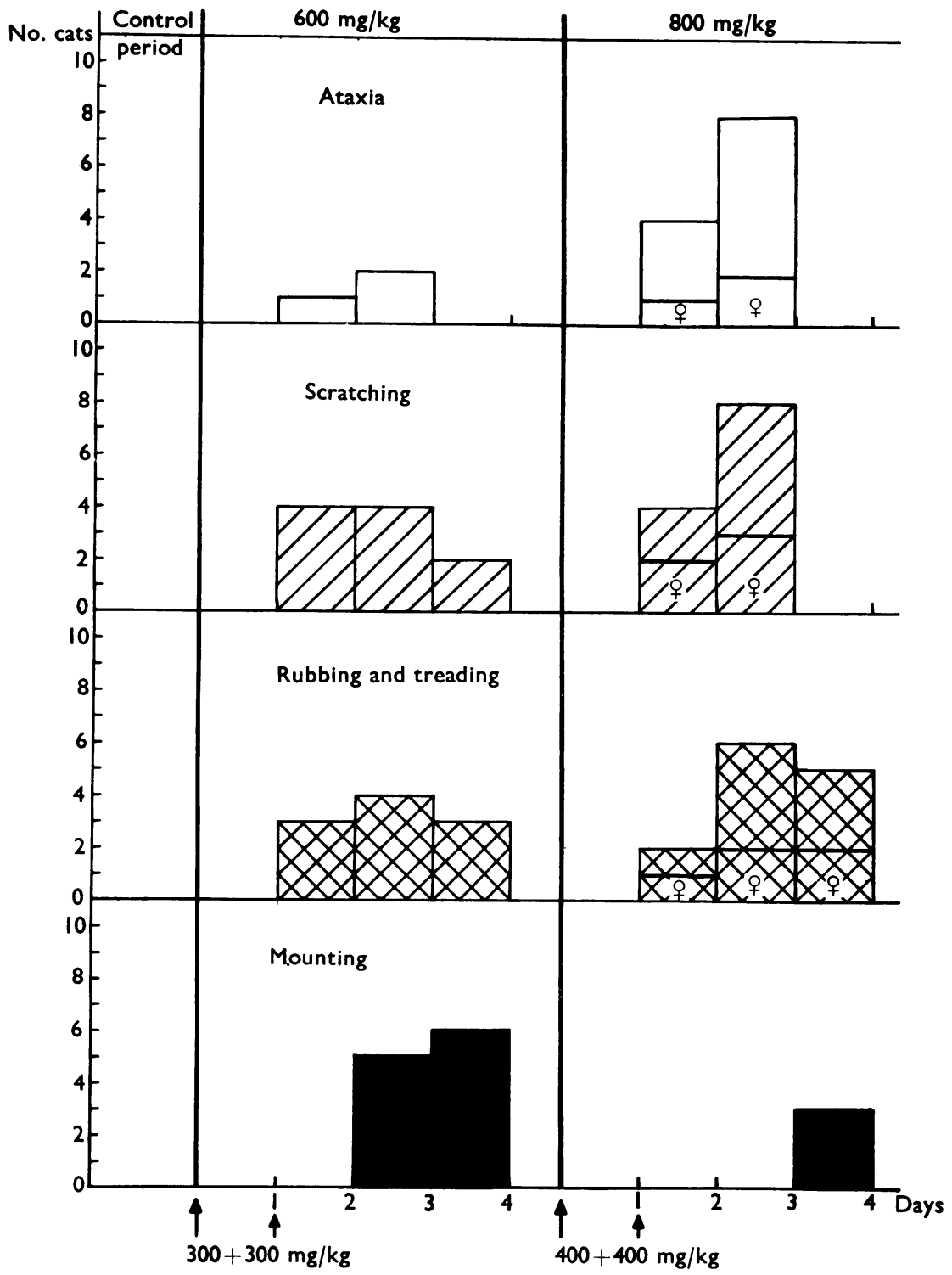

FIG. 1. Incidence of ataxia, scratching, rubbing, treading and mounting in cats up to 4 days after oral doses of $p$-chlorophenylalanine. Ordinate, number of cats showing each sign. Abscissa, time in days. Drugs administered at arrows. Left panel, effects of a total of 600 $\mathrm{mg} / \mathrm{kg}$ on ten adult male cats. Right panel, effects of $800 \mathrm{mg} / \mathrm{kg}$ on mixed groups (two female and five male kittens; one female and two male adults). 
They groomed themselves while sitting, and sometimes groomed each other and part of the time was spent playing with each other or with any other object. Six specific behaviour patterns were recorded for each cat at intervals throughout the day: resting, sitting, grooming, moving, playing, eating.

There were no published dose levels for oral administration of $p$-chlorophenylalanine and so two daily doses of $400 \mathrm{mg} / \mathrm{kg}$ were selected first. At this dose ataxia was pronounced, some animals showed sickness and diarrhoea and they remained motionless in a corner. When the dose was lowered to $300 \mathrm{mg} / \mathrm{kg}$ for 2 days ataxia was reduced and the other side effects did not occur. Single doses of $200 \mathrm{mg}, 400 \mathrm{mg}$ and $600 \mathrm{mg} / \mathrm{kg}$ were also tried; $600 \mathrm{mg} / \mathrm{kg}$ produced severe side effects, and the two lower doses caused only very mild behavioural change. Figure 1 summarizes the type and time of onset of the behavioural changes observed when the drug was given on 2 days. The first signs of drug response were ataxia and what seemed to be skin irritation. The cats scratched more and the main irritation appeared to be localized in the middle of the back. When this was coupled with ataxia they frequently lost balance and lay on the floor trying to scratch their backs; they also swayed slightly when sitting upright. In some animals these signs were observed $24 \mathrm{~h}$ after the first dose, but more cats showed them at $48 \mathrm{~h}$; then the ataxia disappeared although signs of skin irritation sometimes continued for 72 hours. At $48 \mathrm{~h}$ after the first dose of $p$ chlorophenylalanine the cats showed an increase in restlessness and the amount of time spent resting was reduced (Fig. 2). As Koella et al. (1968) had previously

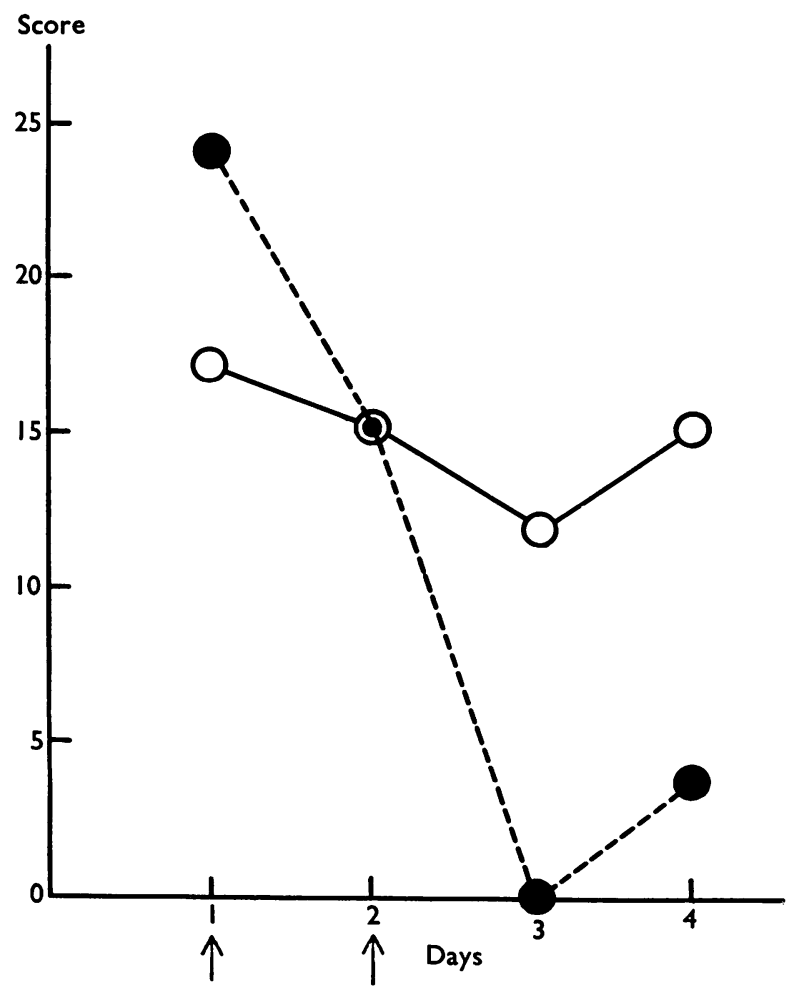

FIG. 2. Effect of two oral doses of $p$-chlorophenylalanine $400 \mathrm{mg} / \mathrm{kg}$ (at arrows) on the activity of a male cat in comparison with that of a control animal. Ordinate, number of times cats were seen resting during observations recorded for 1 min at 15 min intervals over a period of $7 \cdot 25 \mathrm{~h}$ (maximum of 29). Abscissa, time in days. $\bigcirc$, Control cat ; 0 , treated cat. 
reported, the cats miaowed a great deal, and they also made the loud purring " request or greeting call" which is heard when one cat wants contact with another (Moelk, 1944). Both male and female treated cats rubbed against each other and against the untreated animals and stopped playing even when the untreated cats played. When the treated cats were picked up they showed treading and rubbing and when their backs were rubbed they flattened them and turned their tails to one side. This behaviour was very similar to that seen in female cats coming into oestrus, but it was noticed in all male and female kittens, in the adult female and in most adult males. It was noticed that these particular male cats were those which had earlier shown most response to people.

Two of the male kittens and seven of the adult male cats started mounting other males at $72 \mathrm{~h}$ after the first dose of $p$-chlorophenylalanine, and five of these cats showed this behaviour already at 48 hours. The position of the treated cats in the dominance hierarchy influenced the extent of the mounting. The smallest, subordinate males were mounted by the larger males and did not themselves attempt to mount. In a group where two males were equal in dominance, they mounted each other. Sometimes there was considerable antagonism, particularly in untreated cats, towards the cat which kept trying to mount, and then postures of threat and aggression were seen with the cats spitting, growling and striking at each other with their forelegs. A treated cat trying to mount another male cat, first grasped the

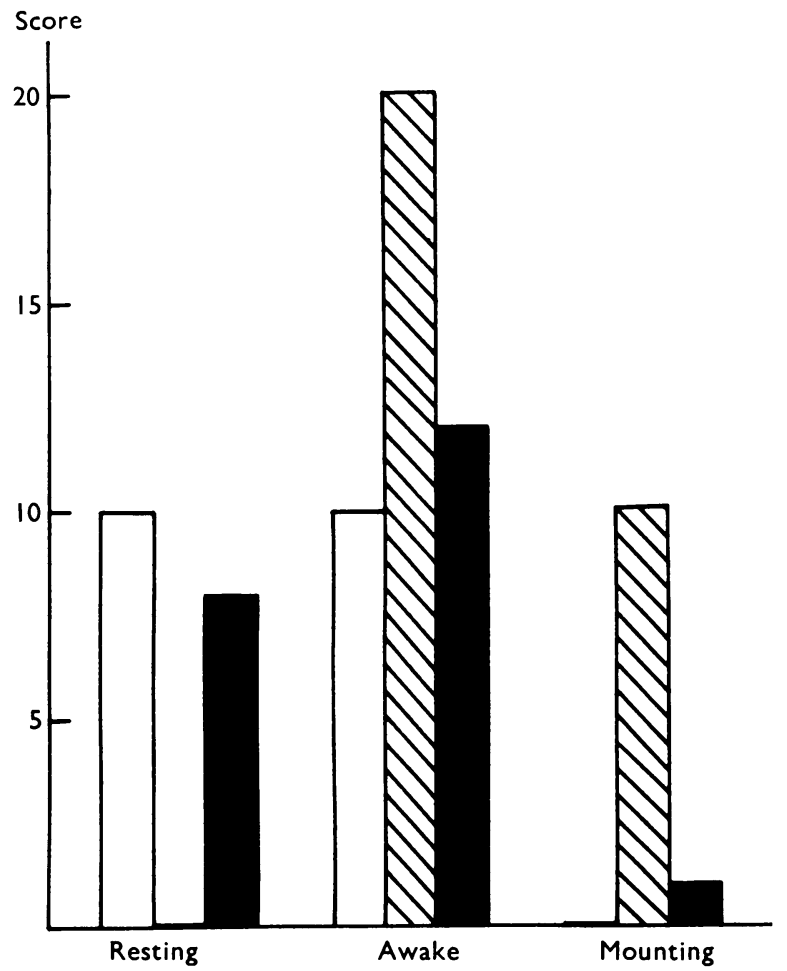

FIG. 3. Behaviour of a male cat during one day before the first of two doses of $p$-chlorophenylalanine $(300 \mathrm{mg} / \mathrm{kg}$ ) (open columns), on the day after the second dose (cross hatched columns), and on the following day when an injection of 5 -hydroxytryptophan $(5 \mathrm{mg} / \mathrm{kg}) \mathrm{was}$ given at 09.30 (solid columns). Activities recorded for $1 \mathrm{~min}$ every $15 \mathrm{~min}$ over a period of $5 \mathrm{~h}$, starting at $10.00 \mathrm{~h}$. Ordinate: score (maximum 20). 
neck of its subject and then moved to stand astride it. They stayed in this position for several minutes with the mounting animal treading and moving its body from side to side, and sometimes the penis was erected and thrusts were made. The mounted cat was very often another treated male animal. One of the factors which increased the frequency of treated animals being mounted was the way in which they rested on the sternum, in a posture very similar to that of an oestrous female ready to mate. The cat being mounted did not co-operate for long and very soon started to growl and moan and eventually it threw the mounting male off by jerking its neck and body. The normal cats and some of the treated animals actively avoided being mounted and kept right out of the way of the approaching animals even if this avoidance restricted their activity. Only male cats mounted whereas cats of both sexes showed scratching and restlessness. Increased sexual activity in the females was restricted to rubbing and treading. This happened in both kittens and the adult cat.

In one experiment two treated male cats ( 9 months old) were left with an untreated female which appeared to be coming into oestrous. The female rubbed against the males and rolled and swayed in front of them. Previously the males had mounted each other as a result of treatment and for some time they continued to do so, but eventually both of them mounted her in turn. Although she assumed a receptive posture and remained still, neither of the males completed copulation.

When 5 -HTP $5(\mathrm{mg} / \mathrm{kg})$ was injected intraperitoneally into cats treated with p-chlorophenylalanine, all abnormal behaviour of both males and females stopped and the cats fell asleep about 70 min later. After one subordinate male cat had been given 5-HTP, it stopped scratching and rubbing and resisted being mounted by another cat treated with $p$-chlorophenylalanine which had often mounted it before. It arched its back, its fur was erected, and it hissed and spat at the approaching male. A dominant male, sexually active after treatment with $p$-chlorophenylalanine, became less active but did not sleep for some time after an injection of 5-HTP; yet the group of cats with which it lived reflected the change in its behaviour; they became playful and less tense, they stopped avoiding it and sat near it instead of as far away as possible. Changes in the behaviour of one male are shown in Fig. 3. Two cats were given only $2 \mathrm{mg} / \mathrm{kg} \mathrm{5-HTP}$ and this dose was also effective in restoring sleep and normal behaviour.

\section{Discussion}

These experiments have shown that $p$-chlorophenylalanine changes the behaviour of cats in a similar way to that found in rats and rabbits. Tenen (1967) found an increased sensitivity to pain in treated rats, and the cats in this study appeared to have an increased sensitivity to skin irritation which resulted in much scratching. The effects of sleep deprivation have already been described by Koella et al. (1968). They were shown by these cats in an increased restlessness and plaintive calling. The treated cats showed an increase in two forms of sexual behaviour. Several of the male cats started to mount other cats in the group and even two male kittens showed this behaviour. Mounting is only rarely seen in groups of cats in the absence of a female in oestrus, and no untreated cats showed this behaviour during the time observations were made. A similar change in behaviour has been seen in male rats (Sheard, 1969 ; Shillito, 1969, 1970 ; Tagliamonte et al., 1969) and although no change in behaviour was seen in female rats, Meyerson (1968) has found that 5-HT 
inhibits oestrus in female rats. The female cats treated with $p$-chlorophenylalanine showed a type of behaviour which is part of the pattern seen in an oestrous female. This pseudo-pro-oestrus behaviour was also seen in some males and particularly in those cats which made a definite response towards, rather than away from, the observers. When 5-hydroxytryptophan was given to the cats, the concentration of 5-hydroxytryptamine in the brain was temporarily increased. The most obvious behavioural result was the return of sleep, but before the animals slept, the abnormal sexual activity stopped and the behaviour of the group reflected this by becoming more normal. The temporary restoration of normal behaviour by 5-HTP supports the view that the depletion of 5-hydroxytryptamine by $p$-chlorophenylalanine was the cause of the behavioural changes. Thus cerebral 5-hydroxytryptamine appears to act as an inhibitor of sexual behaviour in cats and has this role in males and, to some extent, in females.

Cerebral 5-hydroxytryptamine occurs in neurones and in the pineal gland. Airaksinen \& McIsaac (1968) interpreted an increase in the incidence of oestrus in rats treated with $p$-chlorophenylalanine as an action on the pineal gland, since the effect disappeared after pinealectomy. In contrast, hypersexuality in male rats was not abolished by pinealectomy (Tagliamonte et al., 1969), so that the abnormal sexual behaviour produced in cats by the drug can confidently be attributed to a loss in neuronal and not in pineal 5-hydroxytryptamine.

After this manuscript was written, a paper (Ferguson, Henriksen, Cohen, Mitchell, Barchas \& Dement, 1970) appeared describing mounting by male cats treated with $p$-chlorophenylalanine. Whereas most of the authors' cats became vicious after the drug, some of them developed the "affectionate" behaviour towards the observer also seen in a few of our cats. Furthermore, the authors were struck by the fact that the effects of administration of $p$-chlorophenylalanine were "provocatively similar" to those they had observed after depriving cats of rapid eye movement sleep (Dement, 1965).

We would like to thank Mr. P. Tegerdine for his assistance in many ways and we are grateful to Dr. H. Reinert of Pfizers Limited for generous supplies of parachlorophenylalanine.

\section{REFERENCES}

Ahtee, L., Sharman, D. F. \& Vogt, M. (1970). Acid metabolites of monoamines in avian brain; effects of probenecid and reserpine. Br. J. Pharmac., 38, 72-85.

Airaksinen, M. M. \& McIsaAc, W. M. (1968). Estrus cycle in rats: the role of serotonin and norepinephrine. Life Sci., Oxford, 7, (1) 471-476.

Delorme, F., Froment, J. L. \& Jouvet, M. (1966). Suppression du sommeil par la p.chlorométhamphétamine et la p.chlorophénylalanine. C. R. Soc. Biol. 160, 2374-2351.

DEMENT, W. C. (1965). Recent studies on the biological role of rapid eye movement sleep. Am.J. Psychiat. 122, 404-408.

Ferguson, J., Henriksen, S., Cohen, H., Mitchell, G., Barchas, J. \& Dement, W. (1970). "Hypersexuality" and behavioural changes in cats caused by administration of p-chlorophenylalanine. Science, N.Y., 168, 499-501.

Koe, B. K. \& Weissman, A. (1966). P-Chlorophenylalanine. A specific depletor of brain serotonin. J. Pharmac. exp. Ther., 154, 499-516.

Koella, W. P., Feldstein, A. \& Czicman, J. S. (1968). The effect of para-chlorophenylalanine on the sleep of cats. Electroenceph. clin. Neurophysiol., 25, 481-490.

MeYerson, B. J. (1968). Amphetamine and 5-hydroxytryptamine inhibition of copulatory behaviour in the female rat. Annls Med. exp. Biol. Fenn., 46, 394-398.

Moelk, M. (1944). Vocalizing in the house-cat; a phonetic and functional study. Am. J. Psychol., 57, $184-205$.

SHEARD, M. H. (1969). The effect of $p$-chlorophenylalanine on behaviour in rats: relation to brain serotonin and 5-hydroxyindoleacetic acid. Brain Res., 15, 524-528. 
Shillito, E. E. (1969). The effect of p-chlorophenylalanine on social interactions of male rats. Br. J. Pharmac., 36, 193-194P.

ShILLITo, E. E. (1970). The effect of parachlorophenylalanine on social interaction of male rats. Br. J. Pharmac., 38, 305-315.

Tagliamonte, A., Tagliamonte, P., Gessa, G. \& Brodie, B. (1969). Compulsive sexual activity induced by $p$-chlorophenylalanine in normal and pinealectomized male rats. Science, N.Y., 166, $1433-1435$.

Tenen, S. S. (1967). The effects of $p$-chlorophenylalanine, a serotonin depletor, on avoidance acquisition, pain sensitivity and related behaviour in the rat. Psychopharmacologia, 10, 204-219.

Tenen, S. S. (1968). Antagonism of the analgesic effect of morphine and other drugs by p-chlorophenylalanine, a serotonin depletor. Psychopharmacologia, 12, 278-285.

(Received June 5, 1970) 